\title{
Investigation of the Effects of Thermit Welding on the Mechanical Properties of the Rails
}

\author{
Vivien Barna $^{1}$, András Brautigam ${ }^{1}$, Bence Kocsis ${ }^{2}$, \\ Dóra Harangozó ${ }^{2}$, Szaboles Fischer ${ }^{2}$ \\ ${ }^{1}$ Budapest Transport Privately Held Corporation (BKV) \\ Akácfa u. 15, H-1072 Budapest, Hungary \\ \{barnav,brautigama\}@bkv.hu \\ ${ }^{2}$ Széchenyi István University \\ Egyetem tér 1, H-9026 Györ, Hungary \\ \{kocsis.bence,harangozo.dora,fischersz\}@sze.hu
}

\begin{abstract}
This current paper deals with the investigation of the variation of the hardness of the rail steel material in the heat-affected zone (HAZ) of a rail joint made by thermit welding $(T W)$. The tested rail is a normal $R 260$ type rail steel category; its production date is 1977, the rolling mill was Diosgyor (Hungary), rail profile is MÁV 48.5. This rail has not been in railway track before the test. The authors performed hardness tests on the rail head's surface even after the rail welding, as well. After the welding and hardness tests, the rail joint was cut with $+/-200 \mathrm{~mm}$ by a rail cutter and transported to the laboratory. Water jet cutting was applied to shape six longitudinal direction slices with five vertical cutting lines from the rail piece's head. The slices' length was $400 \mathrm{~mm}$, the width of these slices was approx. $10 \mathrm{~mm}$; the TW rail joint was in the mid-point of the slices. Micro-Vickers (HV10) hardness tests were executed on these slices, in the $-150 \ldots+150 \mathrm{~mm}$ interval lengthwise and in the 3, 6, and $10 \mathrm{~mm}$ depth points below the rail head's top surface. As a result, the authors received a very detailed hardness functions of the HAZ of rail joint made by TW. These variation functions were compared to the official Elektrothermit's SoW-5 hardness tests' results. It can be concluded that the variation of the hardness of rail steel in the area of the HAZ correlated with the Elektrothermit's results; however, there were some critical points where significant differences were able to be found. The highest deviation was concluded in $50 \mathrm{~mm}$ distance measured from the axis of welded rail joint. The authors gave possible valuable explanations for these phenomena.
\end{abstract}

Keywords: thermit rail welding; HAZ; heat-affected zone; welded rail joint; Brinell Hardness 


\section{Introduction}

Transportation via railway is an especially highlighted logistical process that highly affects the railway rail itself (in the following, the authors use the single word: rail, instead of railway rail). Many researchers dealt with the rail itself in their research [1-4]. It is worth mentioning the rail wear process and its minimizing in curves [1]; the rail's and wheel's corrugations, and the related modified bearing capacity [2]; hence Kuchak et al. [3] published the finite element modeling of rail dampers that is important regarding the environmental aspects. Kazemian et al. [4] dealt with the condition monitoring of vibration of ballasted tracks in Iran where rail problems were detected. The ballast breakage effect is also an essential phenomenon connecting the environment protection due to the increased demand for ballast screening and dust pollution. Benmebarek and Movahedi [5] investigated the DEM modeling of crushable granular materials, while Sysyn et al. [6] executed laboratory tests with the ballast interlocking. Ballast interlocking is a significant area that is related to the geometrical deterioration of the railway tracks, which can be increased by geosynthetic inclusions.

In the case, precise geodetical measurements and complex integrated infrastructural are discussed regarding railways, the publications of Kampczyk and Dybel [7], as well as Matejov and Sestakova [8] can be instanced. The BIM in railway [8] became an up-to-date solution for design, planning, and of course, construction, maintenance, and diagnostics. The laser scanner technology [7] is adequate for receiving huge and helpful 3D point cloud and surfaces in them planning procedure is able to be eased.

This current paper aims to investigate the welded rail joints from the aspect of the hardness variation, mainly in the heat-affected zone (HAZ). For the understanding of rail joints and welding, the authors introduce the relevant knowledge, bases related to them.

The particular cross-section of the rail is manufactured by rolling, which borders the length of the rods/blocks. It stimulated the development of different rail connection technologies. Permanent and non-permanent rail joints also exist which have to meet the following requirements [9]:

- be able to bear with dynamic vertical and lateral loads in the absence of continuity;

- the formation or limit the size of altitude and horizontal steps between the rail ends;

- secure the movements of the rail ends caused by longitudinal loads (dilatation) without damaging the structure beside appropriate fishplate resistance;

- contain as few parts as possible; 
- be easy and fast to construct and to change parts;

- meet the requirements of the interlocking and signaling system and general railway safety.

Rail joints can be permanent and non-permanent types [10]. The most common permanent type rail joint is the rail welding. The authors only deal with the welded rail joints in this article.

Welding technologies provide a possibility for permanent rail joints. These can be divided into two groups: fusion and pressure welding techniques (however, some railway companies apply arc welding). The most commonly used pressure technology is the flash-butt welding. In contrast, arc and thermite welding (Fig. 1) are the most frequent fusion techniques (identifications detailed in MSZ EN ISO 4063:2016 [11]).

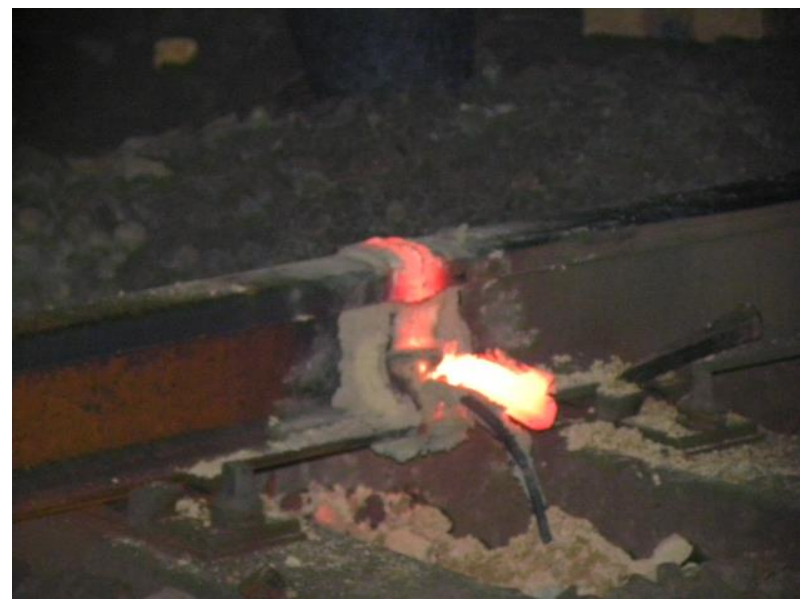

Figure 1

Thermite welding (own made photo of S. Fischer)

Thermite welding was patented in 1895 in the German Empire and is still considered significant in the present. Although however, in constructing new rails, flash-butt welding took the lead, respecting the quantity. Still, in the case of maintenance and closing welds of standard gauge railways and subways, thermite welding became the most widespread technology. A chemical reaction takes place during the process; iron-oxide is reduced to pure iron by aluminum accompanied by heat generation while aluminum-oxide forms (Eqs. 1-3).

$$
\begin{aligned}
& 3 \mathrm{FeO}+2 \mathrm{Al}=3 \mathrm{Fe}+\mathrm{Al}_{2} \mathrm{O}_{3}+679 \mathrm{~kJ} \\
& \mathrm{Fe}_{2} \mathrm{O}_{3}+2 \mathrm{Al}=2 \mathrm{Fe}+\mathrm{Al}_{2} \mathrm{O}_{3}+831 \mathrm{~kJ} \\
& 3 \mathrm{Fe}_{3} \mathrm{O}_{4}+2 \mathrm{Al}=9 \mathrm{Fe}+4 \mathrm{Al}_{2} \mathrm{O}_{3}+782 \mathrm{~kJ}
\end{aligned}
$$


The welding process consists of the following steps:

- a fireproof mold is applied to the rail, fixed by a clamping device to the rail ends;

- the material of the rail is medium or high carbon steel $(0.38 \ldots 1.07 \%)$ [12], which needs proper preparation before welding. The large crosssection also requires a preheating;

- the mixture of aluminum powder and iron oxide is poured into an adequate crucible and ignited with the help of barium peroxide $\left(1300{ }^{\circ} \mathrm{C}\right)$, then loaded into the prepared mold. Nowadays, durable molds are replaced by prepared disposable crucibles; the loading into the mold is an automatic process through a tap at the bottom of the crucible. The thermite steel is followed by the slag to the mold and also to the slag bowls outside the mold. The overheated thermite steel (might be $2400{ }^{\circ} \mathrm{C}$ hot) melts the rail ends, forming a continuous joint.

The high temperature of the welding process changes the pearlitic microstructure and the mechanical properties of the rail steels inevitably [13-15]. An especially hard cross-section can be found in the heat-affected zone (HAZ), leading to fatigue fracture. A softer 'zone' created by partial cementite 'spheroidization' with reduced hardness and strength can be the spot of plastic deformation, which is a significant problem for maintenance. Most of the literature only deals with one or the other phenomena, but they should be handled together. The division of the heat-affected zone into three parts is presented in Fig. 2.

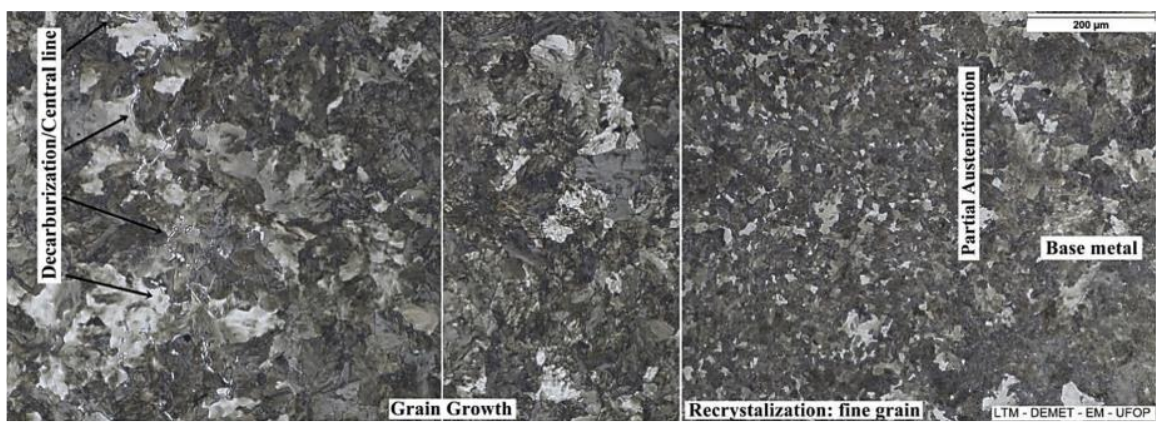

Figure 2

Changes of microstructure in the cross-section of the rail head, near the welded joint [13]

However, another study [16] confutes the significant effect of the retardation of cooling, except to reduce the maximum hardness in the HAZs of alloy rails by about 1-3 HRC.

Figure 3 presents a detailed hardness test. The centerline of the weld under the contacting surface shows a hardness of approximately $300 \mathrm{HV}$. This value is reduced by $50 \mathrm{HV}$ at a distance of $20 \mathrm{~mm}$ from the centerline [14]. Thus, the hardness of the web of the rail is higher than in the case of rail head and foot. 
In the case of aluminothermic weldings, the lower hardness of the weld can be caused by the changed chemical composition according to the applied welding material. Still, the hardness of the weld connot be less than the hardness of the base steel, which can be eliminated by proper material choice [17]. More studies demonstrate the applicability of the higher hardness limit of $350 \mathrm{HV}$ [18-19].

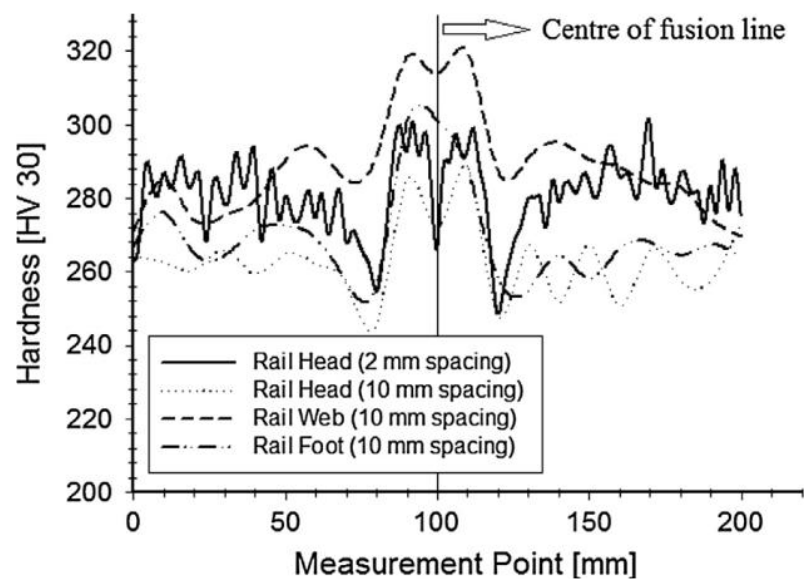

Figure 3

Hardness values in different cross-sections across the weld collar [14]

\section{Methods and Applied Materials}

In this paper the authors examined a TW rail joint based on the variation of hardness of the rail head in the HAZ. The current rail has not been built into the track, it has not been 'suffered' from traffic load anytime. The rail profile was MÁV 48.5 (see Fig. 4), the rail steel category was R260 according to the EN 13674-1 standard, the production year was 1977 . The applied TW technology was SoW-5. The welding was made by the Budapest Transport Privately Held Corporation (BKV).

After the welding process, the rail piece was cut to 60 centimeters length from the rail, using a 'quick disc cutter' (i.e. rail cutter). The TW rail joint was in the middle of this rail lengthwise. In this manner, the measured hardness values of the rail joint and the HAZ were not affected by the heat input during cutting. In the laboratory the $+/-150 \mathrm{~mm}$ long section was considered. Hardness tests were executed on the rail head's surface using a a Sauter HMO-3 type instrument, which measures in Leeb scale that is transformed into HB unit.

This above-mentioned TW rail joint was then examined in the laboratory of Audi Hungaria Faculty of Automotive Engineering at Széchenyi István University, 
whose rail head was cut into six slices with a high-pressure water jet cutter (see Fig. 4). The slices had equal width; the cutting planes were vertical and parallel to the longitudinal axis. The advantage of this cutting technology is that the material to be tested is not exposed to heat. Furthermore, the separation is done mechanically, so the cut surface is smooth, free of burrs, and no hardening occurs, so the hardness values of the welding environment are not affected by the cut. Only one side of the cut rail slices was ground flat (i.e., only one side of the originally connecting surfaces was tested), then hardness tests were executed in the 3,6 , and $10 \mathrm{~mm}$ depth measured from the rail's top surface. The measurements were performed at every 5 millimeters in the whole $+/-150$ mm length.

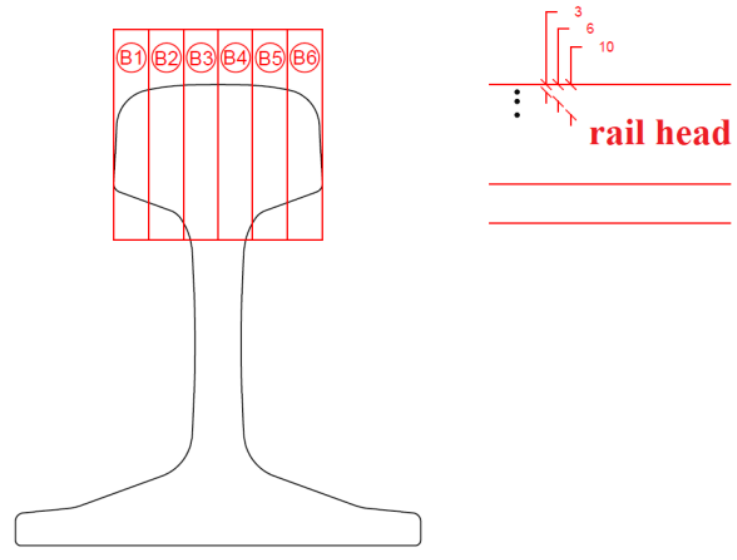

Figure 4

Scheme of the cutting of the rail head for further hardness test (slice 'B6' is at the inner gauge corner)

In the laboratory, the measured hardness values were reported in Vickers hardness (HV10), so for the sake of clarity, the authors converted the results to Brinell Hardness (HB) and displayed them in the tables. The instrument was a KB 30/KB Prüftechnik automatic micro-hardness tester machine. The measured values can be assumed as symmetric schemes related to the welded rail joint mid-axis. Due to the supposed same properties of the welded rail and the TW rail joint in both directions, the water jet cutting was performed only on the rail piece to the right of the TW rail joint's center (i.e., the right-hand side is seen from the track axis).

As a result, the authors prepared a very detailed hardness 'map' of the hardness variation of HAZ of TW rail joint. Furthermore, these variation functions were compared to the official SoW-5 functions, and the own measurements on the rail head's surface. The connecting results are detailed in Chapter 3. 


\section{Results and Discussion}

The measured Brinell Hardness values of the tested TW rail joint are published in Figs. 5-7. The values (series B1...B6) are related to 3, 6, and $10 \mathrm{~mm}$ below the surface. These figures also contain the results of the own hardness tests related to the rail head's surface (i.e., these values are average values considering more measurements at these lines). In Figs. 5-7 there is an additional line: it is the official SoW-5 hardness series [20] measured by Elektro-Thermit.

It can be concluded that the approximate shape of the functions are quite similar, and they have steps/jumps in the $40 \ldots 50 \mathrm{~mm}$ interval from the TW rail joint's axis, which is the outer borderline of the HAZ.

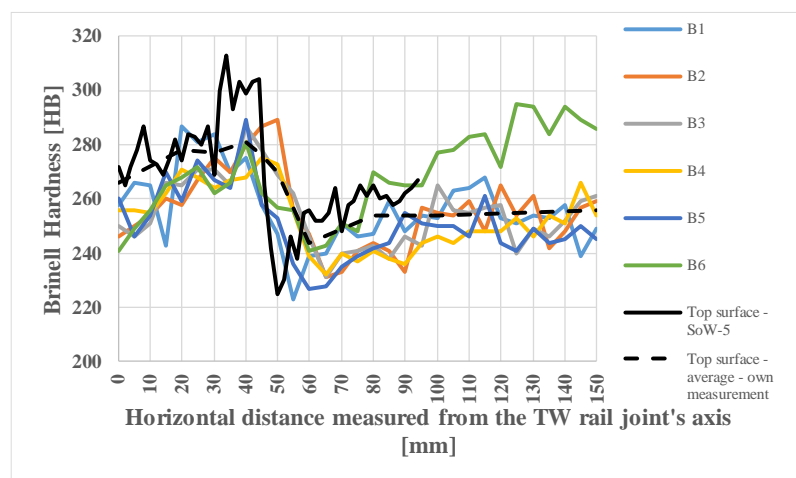

Figure 5

Results of hardness test in the $3 \mathrm{~mm}$ depth measured from the rail head's top surface

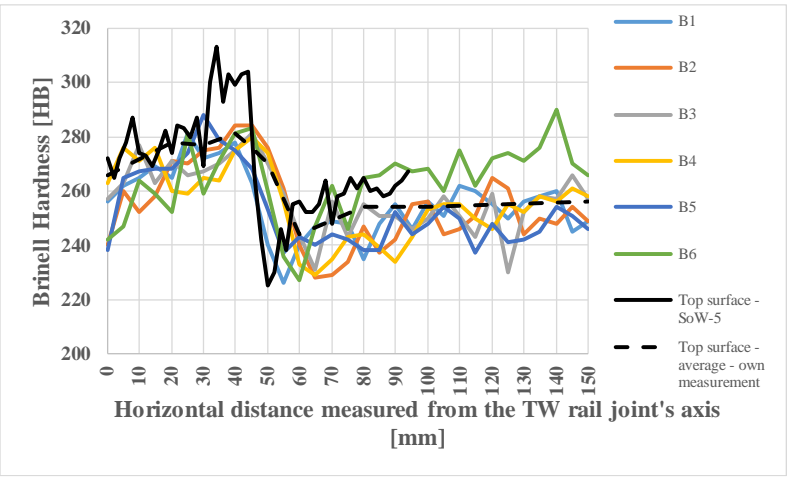

Figure 6

Results of hardness test in the $6 \mathrm{~mm}$ depth measured from the rail head's top surface 


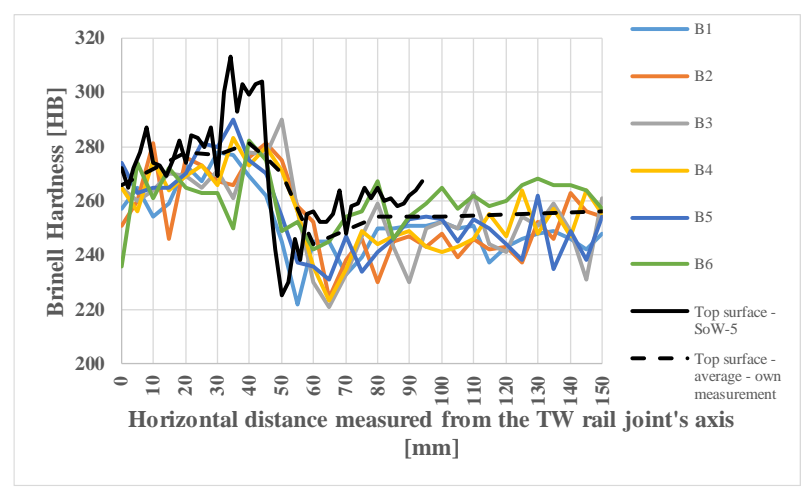

Figure 7

Results of hardness test in the $10 \mathrm{~mm}$ depth measured from the rail head's top surface

The ratios (rates) are given in Figs. 8-10, considering and comparing with SoW-5 technology's official hardness diagram's values [20], they are calculated in percentages. If the received rate (percentage) is higher than $100 \%$, the authors' measured results are higher than the official values from the SoW-5 diagram. In the SoW-5 diagram the values are presented in each $2 \mathrm{~mm}$ values lengthwise; the authors' measurements were executed in every $5 \mathrm{~mm}$ point. It is resulted that the rates are calculated only in every $10 \mathrm{~mm}$ point because the authors didn't want to interpolate the hardness values that can cause inadequate approximation.

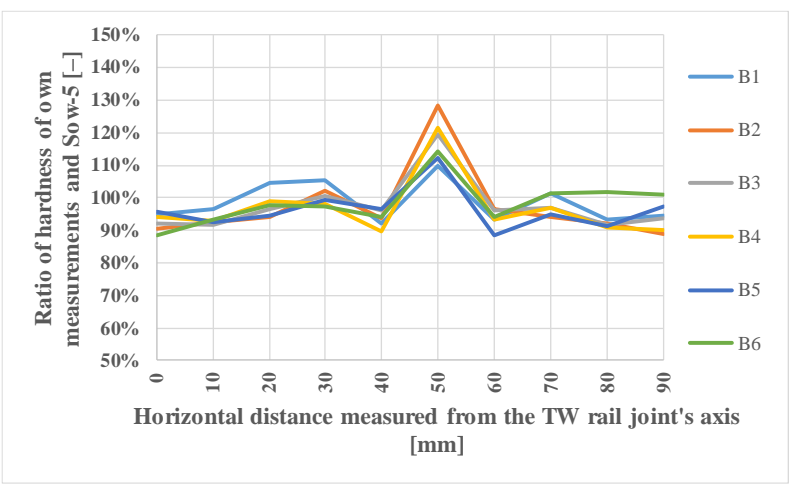

Figure 8

Hardness ratio in the $3 \mathrm{~mm}$ depth measured from the rail head's top surface 


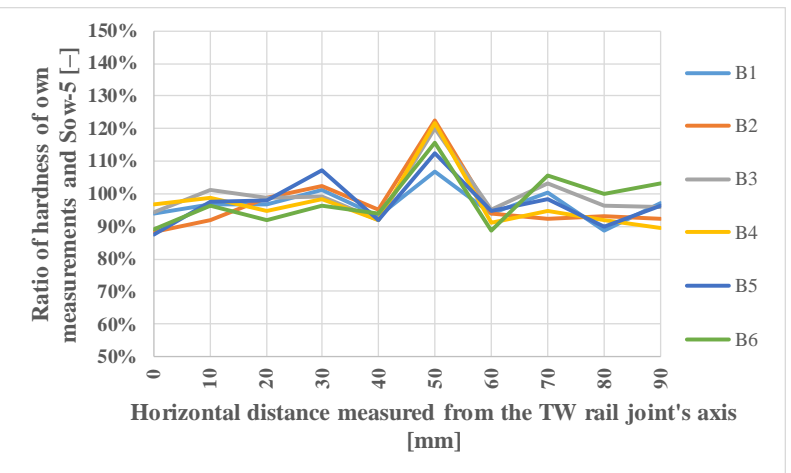

Figure 9

Hardness ratio in the $6 \mathrm{~mm}$ depth measured from the rail head's top surface

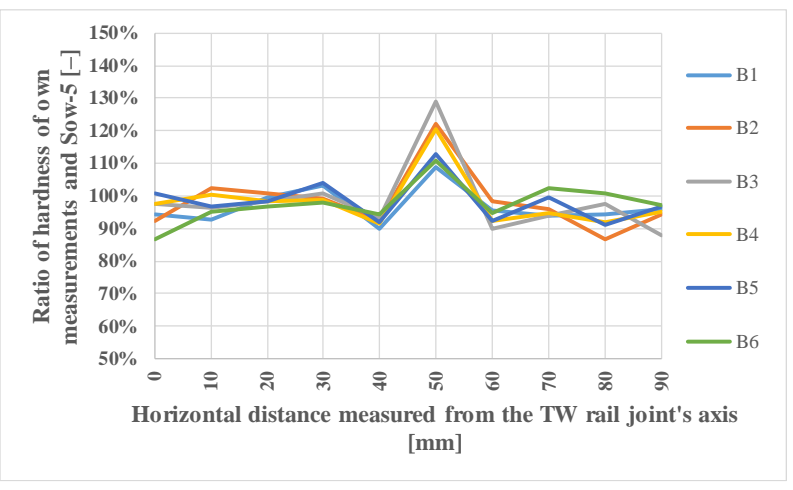

Figure 10

Hardness ratio in the $10 \mathrm{~mm}$ depth measured from the rail head's top surface

There are significant peak values (approx. 110-130\%) in the $50 \mathrm{~mm}$ zone from the axis of the welded rail joint in every depth value (i.e., 3, 6, and $10 \mathrm{~mm}$, respectively). Next to them, the average values seem to be in the $90-100 \%$ range.

Additionally, the authors introduce a figure about the surface measurements in Fig. 11. The base calculation procedure is the same as in Figs. 8-10, but it has to be mentioned that own made hardness measurements on rail's surface were performed at the field, even after the rail welding. It means that the signed distances are not as accurate as in the laboratory. The field hardness tests were executed by a Sauter HMO-3 type instrument. 


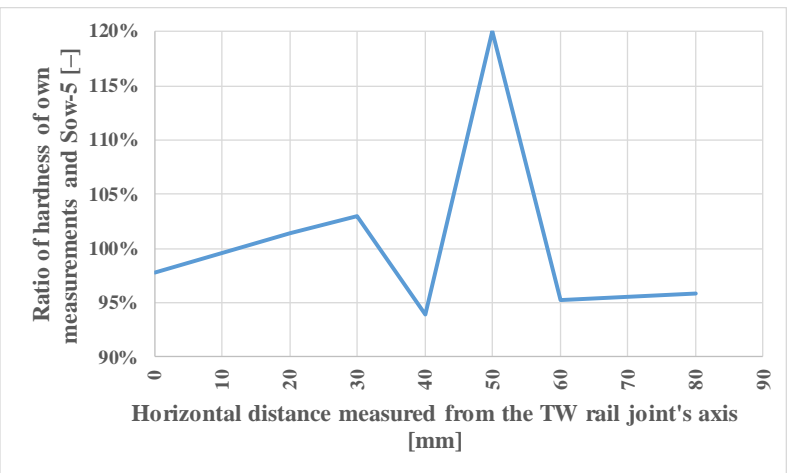

Figure 11

Hardness ratio on the rail head's top surface

The differences can be explained with the following statements:

- the rail and air temperature values might not have been the same in the two compared procedures, i.e., during the thermit welding.

- The different cooling speed values of the welded joints and the connecting rails can cause significant differences also in hardness values.

- Considering the B1 and B6 slices (due to symmetry), mainly in the $+70 \ldots+150 \mathrm{~mm}$ zone, the differences in the measured hardness values can be explained by the base material's not exact purity and homogenity. This variation cannot be found neither in the pairs B2-B5, nor B3-B4.

- Unfortunately, it is not evident and precisely known whether which rail rolling mill produced the rail sample that the Elektro-Thermit considered. The quality of the rail steel material exceptionally influences the hardness values of the rail, mainly the hardness of the material far from the surface. The quality of the rails, which were rolled in Diósgyör in the past, is not sufficient. The measurable hardness values of this kind of rail sometimes cannot reach the qualification Brinell Hardness values, not only on the rail head's surface even in higher depths; it is a property of this rail steel materials).

- Differences in welding practice and technology: width of the set welding gap, thickness of the sealing, width of the casting moulds, effect of the surface quality during hardness test, fineness of the grinding after welding. The time difference in pre-heating, application of crucible and ignition, time parameters in technology, and their increasing in given cases are factors in which you shouldconsider the welding practice (human factor). 
The relatively high values $(110-120 \%)$ in Figs. $8-11$ can be resulted by the significantly quick cooling procedure at the borders of the ceramic casting moulds (see Figs. 2 and 3). Below the casting moulds, the steel temperature can remain $700-750{ }^{\circ} \mathrm{C}$, or higher. It causes that the rail steel can be quenched. The rail parts/sections where there is no covering by casting moulds, the rail temperature remains below $650{ }^{\circ} \mathrm{C}$. In these zones, the steel can't be quenched, and they are the so-called softening zones. However, in the zones where the rail temperature is below $650{ }^{\circ} \mathrm{C}$, the softening effect can't be seen.

\section{Conclusions}

The authors presented the results of laboratory and field tests of a welded rail joint. The welding technology was SoW-5 type thermit welding (TW), while the rail profile was MÁV 48.5. This rail has not been in railway track before the test. The investigation focused on the variation of the hardness of rail steel in the HAZ of the welded rail joint. The authors carried out hardness tests on the rail head's surface even after the rail welding, as well. After the field hardness tests and welding, the rail joint was cut with $+/-200 \mathrm{~mm}$ by a rail cutter and transported to the laboratory. Water jet cutting was applied to shape six longitudinal slices from the rail piece's head. Micro-Vickers (HV10) hardness tests were made on these slices, in the $-150 \ldots+150 \mathrm{~mm}$ interval lengthwise and in the 3,6 , and $10 \mathrm{~mm}$ depths. The HV10 hardness values were transformed to Brinell Hardness, and the field measurements' Leeb scale was also exchanged to Brinell Hardness.

The results were drawn in charts, figures, in which the Elektro-Thermit's official hardness function was taken into consideration related to HAZ of welded rail joint made by SoW-5 TW technology.

The authors received significantly detailed results because these measurements have not been published earlier in other research papers in different depths and in different horizontal positions in the rail head. The hardness measurement series was compared the SoW-5 technology's hardness test's results.

Based on the comparisons, the authors were able to draw conclusions. They stated that the received hardness tests functions are quite similar to the SoW-5's diagram (shape and scheme). It can be seen a significant peak at the position of $50 \mathrm{~mm}$, measured from the axis of the welded rail joint (see Figs. 8-11, the mentioned value is approx. 120-130\%). In the most cross-sections, the authors' results are in accordance with the SoW-5 function; they are in the 90-100\% range (see Figs. 811). There are not too high differences in hardness values considering different depths and positions in the rail head. There is an outlier, e.g. B6 slice.

The authors gave all the possibilities that can be the reasons for the differences in measured hardness values. The tested rolled rail from the rolling mill Diósgyör (Hungary) and the applied technology, as well as its details, properties significantly influence the results. 
The authors conceive the possible further investigation as below:

- more types of welding technologies can be considered, e.g., flash butt welding, electric arc welding; and the main differences can be concluded with detailed comparison,

- heat treated and/or quenched base steel materials can be taken into consideration, etc.

\section{Acknowledgement}

The authors would like to express their thanks for the technical support of Budapest Transport Privately Held Corporation (BKV) and the laboratories of Audi Hungaria Faculty of Automotive Engineering of Széchenyi István University.

\section{References}

[1] M. Kurhan, D. Kurhan, R. Novik, S. Baydak, N. Hmelevska, Improvement of the railway track efficiency by minimizing the rail wear in curves. IOP Conference Series: Materials Science and Engineering, Vol. 985, No. 1, 2020, 012001

[2] V. Kovalchuk, M. Sysyn, Y. Hnativ, A. Onyshchenko, M. Koval, O. Tiutkin, M. Parneta, Restoration of the Bearing Capacity of Damaged Transport Constructions Made of Corrugated Metal Structures. Baltic Journal of Road and Bridge Engineering, Vol. 16, No. 2, 2021, pp. 90-109

[3] A. J. Tigh Kuchak, D. Marinkovic, M. Zehn, Finite element model updating - Case study of a rail damper. Structural Engineering and Mechanics, Vol. 73, No. 1, 2020, pp. 27-35

[4] M. Kazemian, F. Astaraki, M. R. Movahedi, A. Taheri, Condition monitoring of vibration at weak parts of rail for ballasted railway tracks in Iran. Journal of the Korean Society for Railway, Vol. 24, No. 6, 2021, pp. 544-551

[5] A. Benmebarek, M. R. Movahedi, DEM modeling of crushable grain material under different loading conditions. Periodica Polytechnica Civil Engineering, Vol. 65, No. 3, 2021, pp. 935-945

[6] M. Sysyn, O. Nabochenko, V. Kovalchuk, M. Przybyłowicz, S. Fischer, Investigation of interlocking effect of crushed stone ballast during dynamic loading. Reports in Mechanical Engineering, Vol. 2, No. 1, 2021, pp. 65-76

[7] A. Kampczyk, K. Dybel, Integrating surveying railway special grid pins with terrestrial laser scanning targets for monitoring rail transport infrastructure. Measurement: Journal of the International Measurement Confederation, Vol. 170, 2021, 108729 
[8] A. Matejov, J. Šestáková, The Experiences with utilization of BIM in railway infrastructure in Slovak Republic and Czech Republic. Transportation Research Procedia, Vol. 55, 2021, pp. 1139-1146

[9] J. Gajári, Railways I., 1983, Tankönyvkiadó, Budapest, in Hungarian

[10] A. Németh, S. Fischer, Investigation of glued insulated rail joints applied to CWR tracks. Facta Universitatis-Series Mechanical Engineering, 2021, 7642

[11] MSZ EN ISO 4063:2016: Welding and allied processes. Nomenclature of processes and reference numbers, $28 \mathrm{p}$.

[12] MSZ EN 13674-2:2020: Railway applications. Track. Rail. Part 2: Switch and crossing rails used in conjunction with Vignole railway rails $46 \mathrm{~kg} / \mathrm{m}$ and above, $112 \mathrm{p}$.

[13] R. R. Porcaroa, G. L. Fariaa, L. B. Godefroida, G. R. Apolonioa, L. C. Cândidoa, E. S. Pinto: Microstructure and mechanical properties of a flash butt welded pearlitic rail. Journal of Materials Processing Tech., Vol. 270, 2019, pp. 20-27

[14] Y. Sarikavak, O. S. Turkbas, C.Cogun: Influence of welding on microstructure and strength of rail steel. Construction and Building Materials, Vol. 243, 2020, 118220

[15] C. Meric, E. Atik, S. Sahin: Mechanical and metallurgical properties of welding zone in rail welded via thermite process. Science and Technology of Welding and Joining, Vol. 7, No. 3, 2002, pp. 172-176

[16] L. C. Schroeder, D. R. Poirier The Mechanical Properties of Thermite Welds in Premium Alloy Rails. Materials Science and Engineering, Vol. 63, 1984, pp. 1-21

[17] BSI Standards Limited, Railway applications. Track. Aluminothermic welding of rails. Qualifications of aluminothermic welders, approval of contractors and acceptance of welds. 2017

[18] W. A. Bruce, B. C. Etheridge, V. R. Arnett, Development of Heat-Affected Zone Hardness Limits for In-Service Welding. Tech Report, DOT Project No. 216, ENAUS826BBRUCE, Project No. 82673428, 2009, https://trid.trb.org/view/1475729/ [online, last visited on: 2021.09.28]

[19] Further Development of Heat-Affected Zone Hardness Limits for InService Welding, Proceedings of the $20129^{\text {th }}$ International Pipeline Conference, Canada, IPC2012-90095, pp. 71-81

[20] Elektrothermit, Thermit SoW-5, https://www.elektro-thermit.de/fileadmin/ et/user_upload/PDF/Produktbrosch\%C3\%BCren/SOW5_DEF.pdf [online, last visited on: 2021.09.28] 